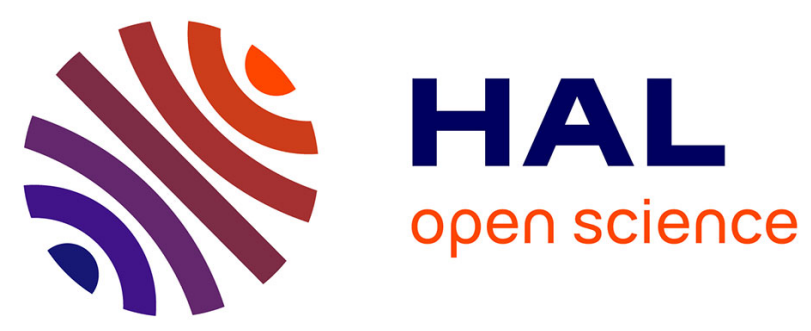

\title{
Multiscale analysis of the transverse properties of Ti-based matrix composites reinforced by SiC fibres: from the grain scale to the macroscopic scale
} Nicolas Carrère, Roger Valle, Thierry Bretheau, Jean-Louis Chaboche

\section{To cite this version:}

Nicolas Carrère, Roger Valle, Thierry Bretheau, Jean-Louis Chaboche. Multiscale analysis of the transverse properties of Ti-based matrix composites reinforced by $\mathrm{SiC}$ fibres: from the grain scale to the macroscopic scale. International Journal of Plasticity, 2004, 20, pp.783-810. 10.1016/j.ijplas.2003.09.001 . hal-00111400

\author{
HAL Id: hal-00111400 \\ https://hal.science/hal-00111400
}

Submitted on 1 Mar 2019

HAL is a multi-disciplinary open access archive for the deposit and dissemination of scientific research documents, whether they are published or not. The documents may come from teaching and research institutions in France or abroad, or from public or private research centers.
L'archive ouverte pluridisciplinaire HAL, est destinée au dépôt et à la diffusion de documents scientifiques de niveau recherche, publiés ou non, émanant des établissements d'enseignement et de recherche français ou étrangers, des laboratoires publics ou privés. 


\title{
Multiscale analysis of the transverse properties of Ti-based matrix composites reinforced by $\mathrm{SiC}$ fibres: from the grain scale to the macroscopic scale
}

\author{
N. Carrere ${ }^{\mathrm{a}, *}$, R. Valle, T. Bretheau ${ }^{\mathrm{c}}$, J.-L. Chaboche ${ }^{\mathrm{a}}$ \\ ${ }^{a}$ ONERA/DMSE, 29 avenue de la Division Leclerc, F-92322 Châtillon Cedex, France \\ bONERA/DMSC, 29 avenue de la Division Leclerc, F-92322 Châtillon Cedex, France \\ ${ }^{\mathrm{c}}$ Laboratoire de Mécanique des Solides, Ecole Polytechnique, F-91128 Palaiseau Cedex, France
}

It is well known that the presence of continuous fibres in $\mathrm{SiC} / \mathrm{Ti}$ composites leads to a high mechanical anisotropy of the composite between the longitudinal and the two transverse directions. But it is also possible that the crystallographic texture of the matrix may lead to a non-negligible anisotropy of the mechanical properties of the composite. The crystallographic orientation of the matrix grains was determined using the Electron BackScattering Diffraction technique. A local texture of the matrix of the composite is thus evidenced. Finite Element calculations are used to determine the stress field in the matrix resulting from an applied transverse loading. The representative mechanical quantities thus determined are discussed in relation with the fundamental mechanisms of plastic deformation of the matrix. Finally, the crystallographic texture of the matrix of the composite is taken into account in the numerical modellings using a three-scale model that combines crystal plasticity, a polycrystalline aggregate model and a periodic homogenization through a Finite Element unit cell for the composite analysis.

Keywords: Composite; Titanium alloy; Crystallography; Texture; Modelling

\footnotetext{
* Corresponding author. Fax: +33-1-4373-4891.

E-mail address: nicolas.carrere@onera.fr (N. Carrere).
} 


\section{Introduction}

Gas turbine engines can be improved by reducing the weight of the rotating components. Due to their high temperature capabilities and good mechanical properties in the fibre direction, unidirectional $\mathrm{SiC} / \mathrm{Ti}$ composites are good candidates for the manufacture of integrally bladed compressor rings, with potential weight savings up to $50 \%$ (Mall et al., 1998). However, significant triaxial stresses being generated in the rotating disc, knowledge of the transverse properties, often weak in these composites (Ohno et al., 1994), is of absolute necessity for both material optimization and structural design.

Consequently, a number of investigations have already been performed on metal matrix composites (MMCs) or even titanium matrix composites (TMCs) subjected to a transverse tensile or creep loading. These investigations were essentially focused on the combined effects of fibre distribution (Brockenbrough et al., 1991) and of internal thermal stresses (Nakamura and Suresh, 1993) or of the fibre/matrix transverse Young's modulus ratio (Lesne et al., 1995) on the transverse response of MMCs, using finite element (FE) models. Some of such studies were performed on TMCs (Dève, 1999; Miracle and Majumdar, 1999; Wu et al., 2001; Ellyin and Xia, 2001). Moreover, interfacial debonding, which seriously affects the transverse behaviour (Nimmer et al., 1991; Li and Wisnom, 1994; Gundel et al., 1995; Cotterill and Bowen, 1996; Warrier et al., 1999), has also been investigated (Needleman, 1992) using the cohesive zone model developed by Needleman (1987) and improved by Tvergaard (1990). Studies related to the transverse response of MMCs have also been performed at the crystallographic scale. They concern either the microstructural deformation modes (Majumdar and Newaz, 1992), or the matrix texture (Poole et al., 1994a; Poole et al., 1994b; Rangaswamy et al., 2000; Gordon and Clyne, 1993), or the crystal plasticity (Needleman and Tvergaard, 1993). Independently, finite element models of polycrystalline aggregates have been developed (Cailletaud, 1987; Pilvin, 1990; Staroselsky and Anand, 2003) as extensions of previous models (Lin, 1957; Kröner, 1961; Berveiller and Zaoui, 1978) in order to describe the macroscopic behaviour of a polycrystalline textured alloy such as the matrix of a MMC. Such models have already been used to determine the macroscopic behaviour of two-phase single crystal superalloys (Méric et al., 1991) or twophase polycrystalline titanium alloys (Feaugas et al., 1997). They are however still under development to describe the mechanical behaviour of polycrystals. They consist in either affine (Masson et al., 2000), tangent (Molinari et al., 2003) or second order (Ponte Castañeda, 1996; Ponte Castañeda and Suquet, 1998) models. However, to the authors' knowledge, no studies concerning the macroscopic transverse behaviour of MMCs have been reported to date, taking simultaneously into account the effects of the interface bond strength, of the internal thermal stresses and of the local texture of the matrix via a polycrystalline aggregate model.

In fact, as regards the SM1140+/Ti-6242 composite under investigation, transverse creep tests have already been performed under vacuum at a temperature of $500{ }^{\circ} \mathrm{C}$. These tests, reported in a previous paper (Carrere et al., 2002), have revealed classical creep curves with the three characteristic stages: primary, secondary 
and tertiary. Using a two-scale approach (fibre/matrix scale and macroscopic scale), it has been shown that the global response strongly depends on the local fibre/matrix interface behaviour. A number of scanning electron microscope (SEM) observations have shown that the only observed damage is interface debonding (Carrere, 2000). As shown in previous papers (Crossman et al., 1974; Ohno et al., 1994; Eggleston and Ritter, 1995), due to the existence of an experimentally determined critical stress $\left(\sigma_{\mathrm{c}}\right)$, two distinct domains were evidenced as a function of the applied stress:

- below $\sigma_{\mathrm{c}}$, a slight damage (fibre/matrix debonding) is observed. After a short primary creep stage, a steady creep rate is attained leading to a long duration test without fracture,

- above this critical stress, damage is generalized, leading to an increase in the secondary creep rate and to the possible failure of the specimen.

FE analysis has been performed in order to confirm these experimental results and to improve the understanding of the operating mechanisms (Carrere et al., 2002). This analysis is based on a rectangular unit cell representative of the hexagonal fibre arrangement in the composite. The fibres are supposed to remain elastic isotropic. The matrix is represented by an isotropic elastoviscoplastic model which was identified from tensile, cyclic and creep tests on a monolithic Ti-6242 matrix. The interfacial zone is described by a debonding law based on Tvergaard's model (Tvergaard, 1990). Modelling, presented in (Carrere et al., 2002), reproduces the characteristic creep stages. Simulations show that the main damage is produced during the loading step. This initial damage can induce the rupture of the interface in the loading direction and then relaxes the stress carried by the fibres. Debonding propagates along the interface and the strain is controlled by the matrix. The creep rate is faster compared to the case wherein a part of the load is carried by the fibre (undamaged interface). Experimental observations coupled with simulations clearly demonstrate the existence of a critical stress. Moreover, experimental and numerical results reveal the major influence of the interface on the global behaviour of the composite. These results, presented in (Carrere et al., 2002) led to a better understanding of the damage mechanisms occurring during a transverse creep test. However, a poor quantitative agreement was found between the experimental and numerical results. The same problem was reported by Durodola et al. (1994) for the longitudinal creep modelling of a SiC/Ti-64 composite. A possible explanation is the difference in behaviour between the monolithic matrix used to identify the parameters of the elastoviscoplastic law and the matrix in the composite. In this respect, Carrere et al. (2001) have shown that the matrix in the composite presents a strong local texture, whereas the monolithic matrix is isotropic. The aim of the present paper is to demonstrate that the local texture of the matrix in the composite may have a large influence on the macroscopic behaviour of the composite. More generally, the influence of different kinds of crystallographic anisotropy of the matrix, on the composite mechanical anisotropy, is also investigated. The numerical analysis involves a three-scale approach, incorporating two simultaneous scale changes, in 
order to bring directly into the overall composite behaviour all the local features of the slip systems activated in each grains of the polycrystalline matrix.

\section{Methodology}

\subsection{Experimental procedure}

The material under investigation is a titanium alloy unidirectionaly reinforced by $\mathrm{SM} 1140+$ fibres (manufactured by DERA-Sigma UK). The matrix is the nearalpha titanium alloy Ti-6242 (6Al-2Sn-4Zr-2 Mo wt.\%) with about $90 \%$ alpha phase (hcp structure) and 10\% beta phase (bcc structure). The SM1140+ fibre (100 $\mu \mathrm{m}$ in diameter) is produced by chemical vapour deposition of $\mathrm{SiC}$ on a tungsten core and possesses an external $4.5 \mu \mathrm{m}$ pure carbon coating (Vidal-Sétif and Valle, 1999; Cheng et al., 1999; Shatwell, 1999) which protects the SiC from chemical reactions during processing and acts as a mechanical fuse. The composite, manufactured by SNECMA using the foil-fibre-foil technique, is a 12-ply plate with a fibre volume fraction of about $35 \%$. The foil-fibre-foil route consists in the consolidation, under vacuum $\left[950{ }^{\circ} \mathrm{C}, 80 \mathrm{MPa}\right.$ (Vassel et al., 1996)], of alternately stacked thin matrix foils (about $100 \mu \mathrm{m}$ in thickness) and fibre mats of aligned monofilaments.

The test specimens were machined in the composite plates, the fibres being oriented at $90^{\circ}$ to the loading axis. The creep tests were performed in a lever type machine, under vacuum in order to avoid oxidation phenomena which would be absent in the gas turbine disc where the continuous fibres are completely embedded in the matrix.

The matrix texture was measured using the Electron BackScaterring Diffraction (EBSD) technique (Carrere, 2001; Carrere et al., 2001). The EBSD samples were mechanically polished in order to permit electron diffraction. The EBSD technique is based on the interaction of the scanning electron microscope (SEM) electron beam with the material, providing a punctual divergent source. The diffraction of these electrons on all the atomic planes of each grain gives a "diffraction pattern" also called "Kikuchi pattern". If the crystal primary unit-cell is known, then the experimental Kikuchi patterns can be compared with the simulated ones. This "pattern recognition" method allows to determine the orientation of each grain in the sample.

\subsection{Numerical procedure}

The numerical simulation is based on FE calculations performed with the FE code ZéBuLoN (2000). Due to the periodic arrangement of the fibres in the matrix, it is possible to isolate a unit cell and define symmetry and boundary conditions which are representative of the whole composite (Fig. 1). In the present work, the generalized plane strain assumption is made in the axial direction ( $\varepsilon_{33}$ uniform). Finally, the macroscopic behaviour is obtained by averaging the local stresses and 


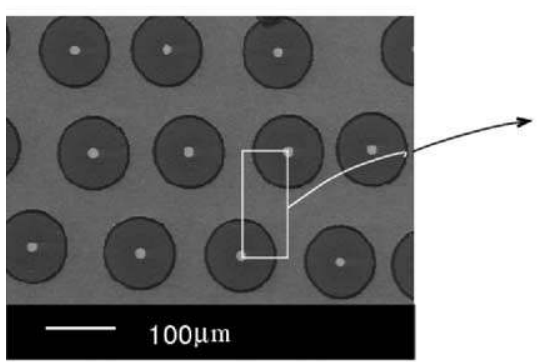

(a)

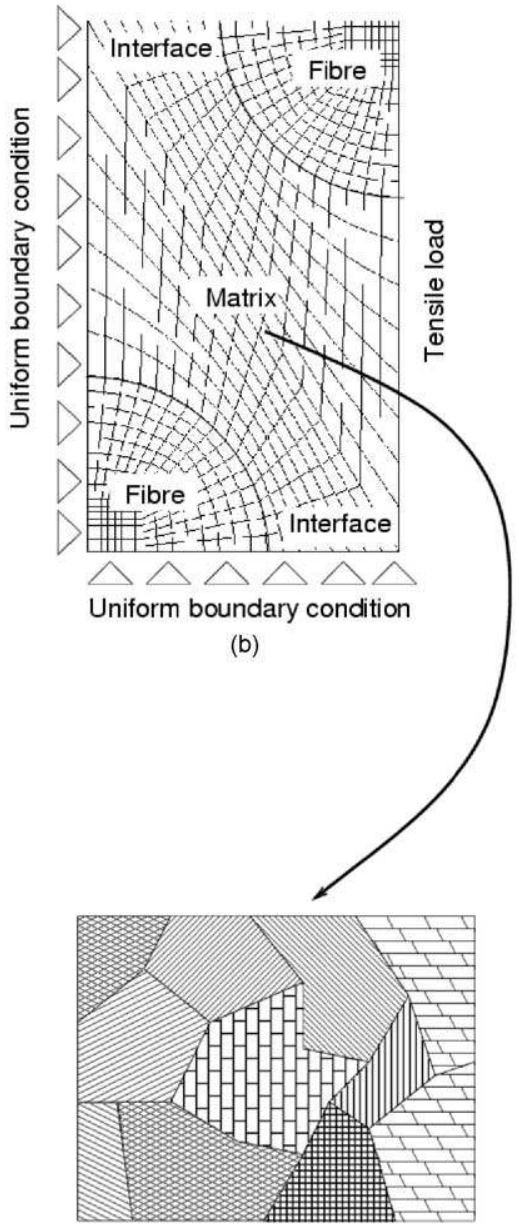

(c)

Fig. 1. Fibre arrangement in the SM1140+/Ti-6242 composite (foil-fibre-foil technique) (a), and the representative unit cell (b). Under each Gauss Point of the FE representative cell the polycrystalline nature of the matrix is taken into account using a polycrystalline aggregate model (c). Note that (c) is a purely formal representation of the polycrystalline matrix; in fact, the model does not take into account the geometry of the grains.

strains over this reference volume. In the present investigation, the $\mathrm{SiC} / \mathrm{Ti}$ composite is only subjected to a transverse loading.

In a first approach, the calculations will be performed in linear isotropic elasticity (for both the matrix and the fibres), and the residual stress field is neglected. The aim of this modelling is to obtain semi-quantitative data regarding the stress field in the matrix and the maximum shear stress which governs plastic deformation mechanisms (Lesne et al., 1995). However, in the present investigation, two cases will be considered: perfectly bonded interfaces and perfectly debonded interfaces (no penetration and no friction). In a second approach, FE calculations will be 
performed taking into account the polycrystalline nature of the matrix, the local matrix texture, the progressive interfacial debonding and the residual stresses. The fibres are characterized by a classical thermo-elastic model. As noted previously, the main damage mechanism during a transverse test is interfacial damage. In previous papers (Carrere et al., 2001, 2002), it has been reported that no damage or porosity is observed before the test. It could be seen on tested samples that the interface between the fibre and the matrix is totally broken; however, no other damage mechanism has been detected. The interfacial behaviour is described by a cohesive zone model (Needleman, 1987; Tvergaard, 1990). This kind of cohesive zone model has already been used to describe the interfacial debonding in composites materials (Chaboche et al., 1997; Pochiraju et al., 2001). Basically, this model gives the local constitutive law between the normal and tangential traction components $\left(T_{\mathrm{n}}, T_{\mathrm{t}}\right)$ and relative displacements $\left(U_{\mathrm{n}}, U_{\mathrm{t}}\right)$ of two points initially superposed and belonging to two different media (Fig. 2). The damage evolution is taken into account by the damage variable $\lambda$ which combines the normal and shear damages as follows

$$
\lambda=\sqrt{\left(\frac{\left\langle U_{\mathrm{n}}\right\rangle}{\delta_{\mathrm{n}}}\right)^{2}+\left(\frac{U_{\mathrm{t}}}{\delta_{\mathrm{t}}}\right)^{2}} \text { where }\langle X\rangle=\left\{\begin{array}{l}
X \text { if } X>0 \\
0 \text { in the other cases }
\end{array}\right.
$$

The non-linear relations between $\left(U_{\mathrm{n}}, U_{\mathrm{t}}\right)$ and $\left(T_{\mathrm{n}}, T_{\mathrm{t}}\right)$ have the form

$$
\left\{\begin{array}{l}
T_{\mathrm{n}}=\frac{U_{\mathrm{n}}}{\delta_{\mathrm{n}}} F(\lambda) \\
T_{\mathrm{t}}=\alpha \frac{U_{\mathrm{t}}}{\delta_{\mathrm{t}}} F(\lambda)
\end{array}\right.
$$

where $F(\lambda)$ is chosen as $F(\lambda)=\frac{27}{4} \sigma_{\max }(1-\lambda)^{2}$ for $0 \leqslant \lambda \leqslant 1$, and where $\sigma_{\max }$ and $\alpha \sigma_{\max }$ are respectively the maximum values of $T_{\mathrm{n}}$ and $T_{\mathrm{t}}$ in pure modes. $\lambda$ varies continuously from 0 (locally bonded nodes) to 1 (locally debonded nodes). $\delta_{\mathrm{n}}$ and $\delta_{\mathrm{t}}$ are the maximum values of the relative displacements $U_{\mathrm{n}}$ and $U_{\mathrm{t}}$ in pure normal and pure shear modes, respectively.

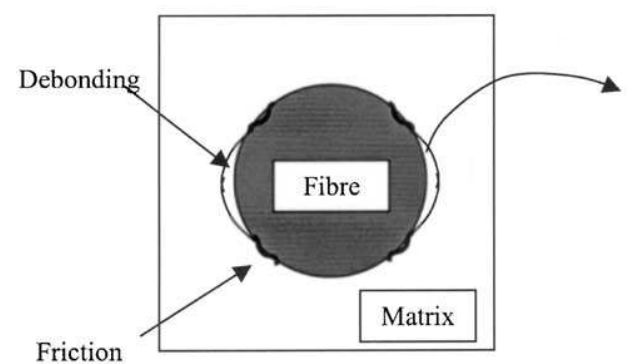

(a)

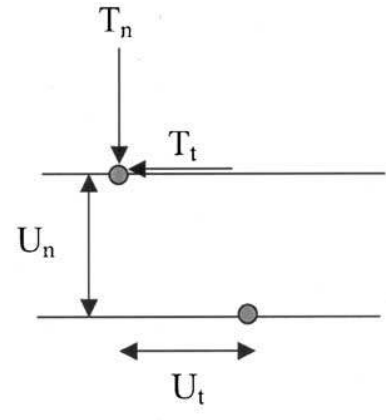

(b)

Fig. 2. Schematic representation of interfacial debonding (a) and modelling of the interfacial zone (b). 
The parameters of this law have been identified from Push-Out tests for the tangential parameters and transverse tensile tests for the normal parameters. The tangential parameters of the Tvergaard's model $\left(\alpha \sigma_{\max }, \delta_{\mathrm{t}}\right.$ and $\left.\mu\right)$ are identified from the results of push-out tests, in order to numerically reproduce the maximum load experimentally observed and the quasi-linear region of the load/displacement curve corresponding to solid friction. To identify the other parameters of the debonding law $\left(\sigma_{\max }\right.$ and $\left.\delta_{\mathrm{n}}\right)$, it is necessary to use a test inducing a normal loading on the interface. In the present case, the transverse tensile test is used. In fact, after an elastic domain without damage, the radial compressive residual stresses are locally overcome (in the loading direction) and the interface damage begins (first knee in the stress/strain curve). It should be noted that these parameters could be related to the critical energy release rates in mode I $\left(G_{\mathrm{I}}^{\mathrm{c}}\right)$ and in mode II $\left(G_{\mathrm{II}}^{\mathrm{c}}\right)$. In the present work, the critical energy release rates in mode I and II will be supposed to be equal.

Due to the importance of the residual stress state in the composite on the macroscopic response (Nimmer, 1990), the whole experimental procedure has been simulated. It may be summarized as follows

- the manufacturing process (consolidation) which consists in a thermomechanical loading (from $950{ }^{\circ} \mathrm{C}, 80 \mathrm{MPa}$ to $20^{\circ} \mathrm{C}$ ),

- the thermal loading to reach the test temperature,

- and, finally, the transverse mechanical loading.

The elastoviscoplatic behaviour of the matrix was characterized by a number of tests (single tensile/compression tests (Baroumes, 1998), cyclic tests (Malon, 2000) and creep tests (Carrere, 2001)) performed on the unreinforced matrix. In order to improve the previous modelling (Carrere et al., 2002), the effect of crystallographic orientations on the viscoplastic behaviour is taken into account by means of a polycrystalline aggregate model (Cailletaud, 1987; Pilvin, 1990, 1996; Cailletaud and Pilvin, 1994). It should however be noted that localized plastic deformation modes, such as dislocation pile-ups, are not taken into consideration in such models. In fact, such mechanisms are of major importance in the presence of large grains in the matrix of the composite (Stohr and Valle, 1975; Valle, 1992; Majumdar and Newaz, 1992) where extended glide planes and thus pile-ups containing a large number of dislocations may lead to a high shear stress at the spearhead, sufficient to break the fibres. However, in the present case, the grains are relatively small; moreover, contrary to previous observations of slip bands in large grains on polished specimens (Majumdar and Newaz, 1992), similar observations have not revealed such intense localized deformation modes in the specimen gauge, except in the not representative necked fracture zone. It is also well known that the grain size effects and the thermal treatment has a great influence on the mechanical properties of the Ti alloys. Consequently, the unreinforced matrix used to identify the constitutive law of the matrix has the same mean grain size as the matrix in the composite. In this context, it should be noted that the number of grains between each fibre is assumed to be sufficiently large to justify the use of the polycrystalline model. Moreover, the thermo-mechanical loading (from $950{ }^{\circ} \mathrm{C}, 80 \mathrm{MPa}$ to $20^{\circ} \mathrm{C}$ ) corresponding to the 
manufacturing process of the composite has been applied to the unreinforced matrix. The behaviour of the textured matrix is described by the crystalline constitutive law (grain scale) and the polycrystalline model (matrix scale) which are presented in Section 3.2.

\section{Results}

\subsection{Texture measurements}

As already mentioned, the Ti-6242 alloy is a near-alpha alloy with about $90 \%$ alpha phase (hcp structure); consequently, the matrix is supposed to be constituted by alpha phase only. Some low-index crystallographic directions and planes in the hexagonal system are given in Fig. 3.

Three different samples have been investigated. The first one is an unreinforced Ti6242 matrix sample used to determine the parameters of the matrix constitutive law (noted as ur-matrix). This sample consists of some thick foils (about $1 \mathrm{~mm}$ in thickness) stacked and consolidated using the same processing cycle as the composite. The second one is an as-received thin Ti-6242 foil (about $100 \mu \mathrm{m}$ in thickness, and noted as ar-matrix) used to manufacture the composite. The third sample is the $\mathrm{SM} 1140+/ \mathrm{Ti}-6242$ composite. The X-ray diffraction technique has been used to measure the textures of both the Ti-6242 plate used to identify the titanium elastoviscoplastic law (ur-matrix) and the Ti-6242 foil used to manufacture the composite (ar-matrix). In the composite sample, the local texture measurements are performed on the $\alpha$-grains of the matrix in the composite, using the EBSD technique. The results are reported in the form of pole figures where the reference axes are given hereunder:

- in the matrix samples, RD corresponds to the rolling direction of the foils, ND to the normal direction and TD to the transverse direction,

- in the composite sample, RD and ND also correspond to the rolling and normal directions of the foils and TD to the fibre direction.

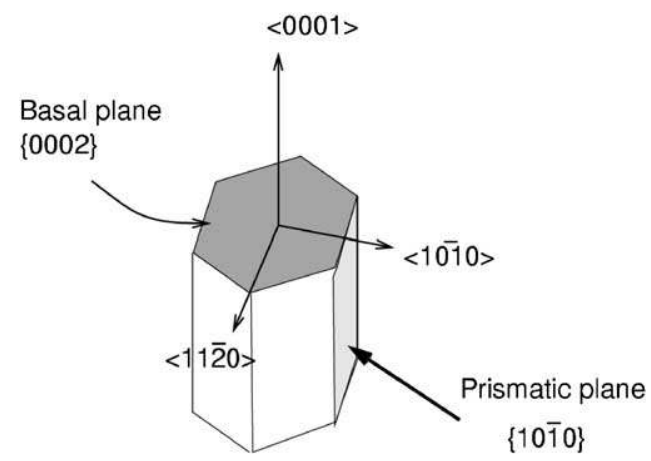

Fig. 3. Some low-index directions and planes in the hexagonal system. 
The results show that the ur-matrix is isotropic and presents a random texture. On the contrary, the matrix foil (ar-matrix) obtained by cold rolling exhibits a strong texture with the (0001) basal planes preferentially oriented parallel to the foil surface (RD,TD). In the case of the matrix in the composite, two zones are evidenced (Carrere et al., 2001). The results are summarized in Fig. 4 where the local pole figures of these two zones are reported

- in the central part of the matrix foils (zone A), the texture is such that the $<0001>$ axis is close to the ND direction. The (0001) basal planes are thus nearly parallel to the (TD, RD) plane. Consequently, there is no evolution of the texture as compared with the ar-matrix.

- in the interfibre spacing (zone B), the initial texture is lost. There is no preferential orientation.

The evolution of the texture could be explained as follows (Carrere et al., 2001)

- in zone A, during the consolidation process, the titanium foils in this zone are essentially subjected to a low plastic deformation, the initial texture of the foils is thus maintained,

- in zone $\mathrm{B}$, during the consolidation process, the matrix is subjected to a severe plastic deformation in order to fill the spaces between the fibres, thus leading to a more random orientation of the grains.

\subsection{Polycrystalline constitutive law}

The main mechanism by which plastic deformation of the Ti-based matrix occurs is dislocation glide. In fact, plastic deformation, by slip, of a crystal (i.e. dislocation glide in a slip plane in the direction of slip) is possible provided that Schmid's law is fulfilled

$$
\tau_{\mathrm{s}}>\tau_{\mathrm{c}}
$$

where $\tau_{\mathrm{s}}$ is the resolved shear stress in the slip plane in the glide direction and $\tau_{\mathrm{c}}$ is the critical resolved shear stress (CRSS).

In the considered temperature range, only prismatic slip and basal slip are possible (Paton et al., 1976). Prismatic slip in the $\{10 \overline{1} 0\}$ prismatic plane in the $\langle 11 \overline{2} 0\rangle$ direction occurs from room temperature. For temperatures greater than $400{ }^{\circ} \mathrm{C}$ the activation of this system is still possible, but the basal slip system $\{0001\}\langle 11 \overline{2} 0\rangle$ could also be activated. For all temperatures, the stress necessary to activate the prismatic slip (CRSS) is lower than that necessary for the basal slip.

In fact, the formulation of the polycrystalline constitutive law involves three steps: the crystalline constitutive model (plastic deformation by slip in each grain), the localization of the macroscopic stress at the level of each individual grain and, finally, the homogenization process to determine the macroscopic plastic deformation. 


\subsubsection{Crystalline constitutive model}

The crystalline constitutive law is written at the grain scale (Cailletaud, 1992). In each grain, the constitutive model gives relations between the resolved shear stress $\left(\tau_{\mathrm{s}}\right)$ on each slip system (s) and the viscoplastic shear strain rate $\left(\dot{\gamma}_{s}\right)$ which is defined

(a)

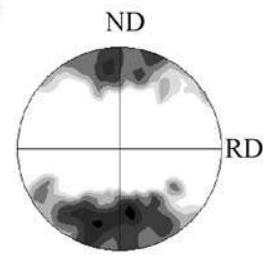

(0001)

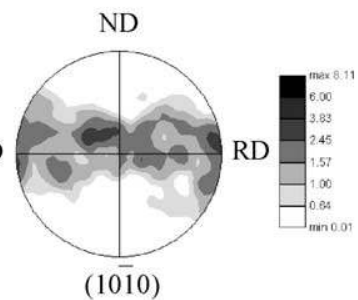

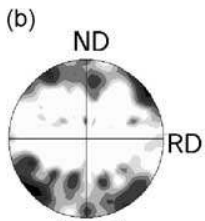

(0001)

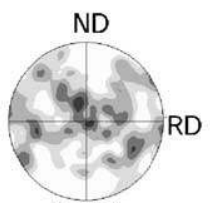

(1010)

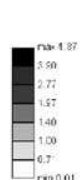

${ }_{\text {ran } 001}^{0.7}$

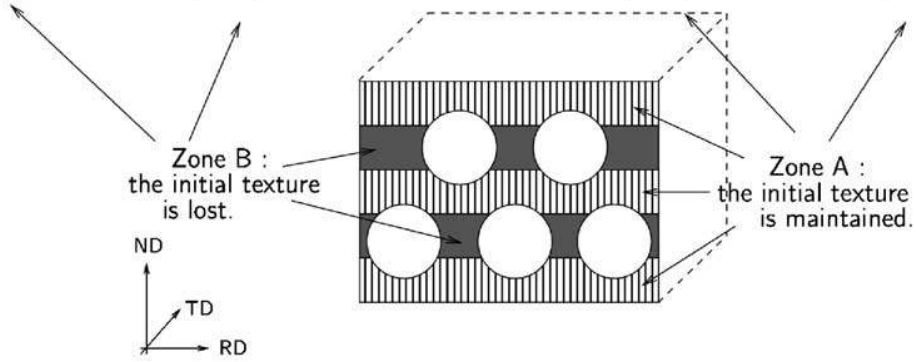

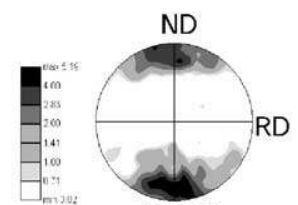

(0001)

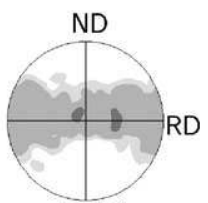

(10ī0)

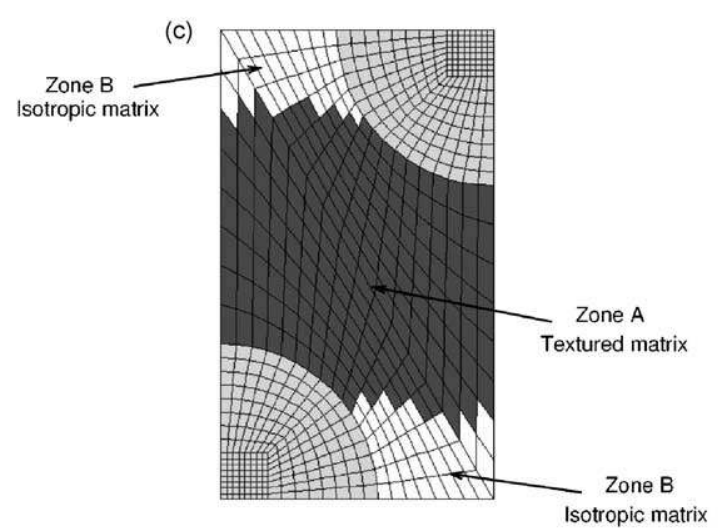

Fig. 4. Poles figures of the ar-matrix foil (a); Local texture of the matrix in the SM1140+/Ti-6242 composite manufactured by the foil-fibre-foil technique (b); FE mesh taking into account the local texture (c). 
by means of a power function of the effective stress. This stress is calculated as the difference between the resolved shear stress and two hardening variables.

For each grain (g) and each slip system (s)

$$
\tau_{\mathrm{s}}=\tilde{m}_{\mathrm{s}}: \tilde{\sigma}_{\mathrm{g}}
$$

$\tilde{m}_{\mathrm{s}}$ being the orientation tensor defined by the relation $\tilde{m}_{\mathrm{s}}=0.5\left(\bar{n}_{\mathrm{s}} \otimes \bar{l}_{\mathrm{s}}+\bar{l}_{\mathrm{s}} \otimes \bar{n}_{\mathrm{s}}\right)$ where $\bar{n}_{\mathrm{s}}$ is the unit vector normal to the slip plane and $\bar{l}_{\mathrm{s}}$ is the slip direction in this plane. $\tilde{\sigma}_{\mathrm{g}}$ is the stress applied to the grain (g) (see next section for details).

The viscoplastic rate $\left(\dot{\gamma}_{s}\right)$ is given by

$$
\dot{\gamma}_{\mathrm{s}}=\left\langle\frac{\left|\tau_{\mathrm{s}}-x_{\mathrm{s}}\right|-r_{\mathrm{s}}}{K}\right\rangle^{n} \operatorname{sgn}\left(\tau_{\mathrm{s}}-x_{\mathrm{s}}\right)
$$

where sgn is the signum function and $<\mathrm{A}>$ is the positive part of $A ; r_{\mathrm{s}}$ represents the isotropic part of hardening i.e. the expansion of the elastic domain for the slip system (s); $x_{\mathrm{s}}$ represents the kinematic part of hardening i.e. the translation of the elastic domain for the slip system (s); $K$ and $n$ are viscosity parameters of the material. The evolution of $r_{\mathrm{s}}$ (hardening law) is given by

$$
r_{\mathrm{s}}=R_{0}+Q_{1} \sum_{r} h_{\mathrm{rs}}\left(1-\mathrm{e}^{-b_{1} v_{\mathrm{s}}}\right)
$$

where $R_{0}$ is the critical resolved shear stress, $Q_{1}$ and $b_{1}$ are material parameters; $v_{\mathrm{s}}$ is the slip rate of the slip system (s) defined by

$$
v_{\mathrm{s}}(\mathrm{t})=\int_{0}^{\mathrm{t}} \dot{\gamma}(u) \mathrm{d} u
$$

$H$ is the interaction matrix, the diagonal part of $H$ giving the self-hardening of the slip system (s), and the term $h_{\mathrm{rs}}(\mathrm{r} \neq \mathrm{s})$ representing the latent hardening i.e. the crossinfluence of the slip system (r) on the hardening of the slip system (s). In the present work, all the terms of the interaction matrix are assumed to be equal to unity.

The evolution of $x_{\mathrm{s}}$ is given by

$$
\left\{\begin{array}{l}
x_{\mathrm{s}}=c_{1} \alpha_{\mathrm{s}} \\
\dot{\alpha}_{\mathrm{s}}=\dot{\gamma}_{\mathrm{s}}-d_{1} x_{\mathrm{s}} \dot{v}_{\mathrm{s}}
\end{array}\right.
$$

where $c_{1}$ and $d_{1}$ are material parameters.

Finally, the deformation rate of the grain is given by

$$
\dot{\tilde{\varepsilon}}_{\mathrm{g}}=\sum_{\mathrm{s}} \tilde{m}_{\mathrm{s}} \dot{\gamma}_{\mathrm{s}}
$$

\subsubsection{Polycrystalline aggregate model}

As mentioned earlier, the only deformation taken into consideration at the single crystal level is the plastic strain $\left(\tilde{\varepsilon}_{\mathrm{g}}\right)$. The elastic deformation is taken into account at 
the aggregate (polycrystalline) level and differs from the single crystal elastic behaviour. In fact, at the polycrystalline scale (homogenization), the total strain $(\tilde{E})$ is equal to the sum of the elastic $\left(\tilde{E}_{\mathrm{e}}\right)$ and viscoplastic $\left(\tilde{E}_{\mathrm{vp}}\right)$ strains. The macroscopic stress tensor $\tilde{\Sigma}$ is thus calculated using the classical constitutive law

$$
\left\{\begin{array}{l}
\tilde{E}=\tilde{E}_{\mathrm{vp}}+\tilde{E}_{\mathrm{e}} \\
\tilde{\Sigma}=\tilde{\tilde{C}}:\left(\tilde{E}-\tilde{E}_{\mathrm{vp}}\right)
\end{array}\right.
$$

where $\tilde{\tilde{C}}$ is the polycrystalline stiffness tensor which is not the same as for the single crystal elastic behaviour.

The constitutive model of the grain being defined, it is now necessary to propose a localization technique in order to characterize the local stress in each grain $\left(\tilde{\sigma}_{\mathrm{g}}\right)$ as a function of the macroscopic stress $(\tilde{\Sigma})$. In the present work, we use the relations proposed by Cailletaud and Pilvin (Cailletaud, 1987; Pilvin, 1990, 1996; Pilvin and Cailletaud, 1990)

$$
\left\{\begin{array}{l}
\tilde{\sigma}_{\mathrm{g}}=\tilde{\Sigma}+\mu \alpha\left(\tilde{B}-\tilde{\beta}_{\mathrm{g}}\right) \\
\tilde{B}=\sum_{\mathrm{g}} c_{\mathrm{g}} \tilde{\beta}_{\mathrm{g}} \\
\dot{\tilde{\beta}}_{\mathrm{g}}=\dot{\tilde{\varepsilon}}_{\mathrm{g}}-D \tilde{\beta}_{\mathrm{g}}\left\|\dot{\tilde{\varepsilon}}_{\mathrm{g}}\right\|
\end{array}\right.
$$

where $c_{\mathrm{g}}$ is the volume fraction corresponding to the grain $(\mathrm{g})$. From a macroscopic point of view, $\tilde{\beta}_{\mathrm{g}}$ is the nonlinear kinematic hardening introduced in order to decrease the stress in the grains, thus taking into account the intergranular interactions. $\mu$ is the shear modulus, $\alpha$ and $D$ are parameters of the localization model. \|\| is a norm.

It should be noted that the variable $\tilde{\beta}_{\mathrm{g}}$ is used in place of the plastic strain in the classical Kröner localization rule. It allows to better take into account strain heterogeneities and the corresponding local stress redistributions. In fact, the model has a self consistent character in the sense that the constant $\mathrm{D}$ in the evolution rule for $\tilde{\beta}_{\mathrm{g}}$ can be adjusted from numerical computations as shown in (Pilvin and Cailletaud, 1990). For the low plastic strain regime, at the onset of plastic flow, it recovers the Kröner rule. For the large strains, it asymptotically tends to the Sachs rule (with a uniform stress localization).

Finally, the macroscopic viscoplastic strain is given by (homogenization)

$$
\tilde{E}^{\mathrm{vp}}=\sum_{\mathrm{g}} c_{\mathrm{g}} \tilde{\varepsilon}_{\mathrm{g}}
$$

\subsubsection{Identification of the polycrystalline constitutive model}

In order to describe the polycrystal, it is necessary to identify the parameters of the polycrystalline aggregate model [Eqs. (9) and (10)] and of the crystalline constitutive model [Eqs. (4)-(8)]. The single crystal and the polycrystalline models 
have been implemented (Cailletaud and Pilvin, 1994) and tested (Barbe et al., 2001), some years ago, in the finite element code ZéBuLoN (Burlet and Cailletaud, 1991; ZéBuLoN, 2000). The identification of the model has thus been performed using the available facilities of this code.

The parameters of the localization model [first equation in (10)] are not "materials parameters" which could be identified from mechanical tests. In the present work, the parameter $\alpha$ was evaluated using the formulation given by Pilvin (1997) and the parameter $D$ could be numerically determined in order to enforce the self-consistency of the model in an average sense (Pilvin, 1997).

For each system, the parameters of the crystalline constitutive model [Eqs. (4)-(8)] have been identified from tensile tests, cyclic tests and creep tests performed on the monolithic Ti-6242 matrix, for a large temperature range (from $20{ }^{\circ} \mathrm{C}$ to $900{ }^{\circ} \mathrm{C}$ ). This material is isotropic, then an isotropic distribution of the orientations of the grains is chosen; it consists in 40 equivalent orientations $\left(\forall g, c_{\mathrm{g}}=1 / 40\right)$. Note that when the parameters of the polycrystalline aggregate model and of the crystalline constitutive model are determined, it is possible to model a textured material by changing the orientation distribution of the grains.

Evaluation of the model parameters was done using quite a large data base : several tensile tests, relaxation tests and cyclic tests for temperatures ranging from $900{ }^{\circ} \mathrm{C}$ to $20^{\circ} \mathrm{C}$. Some creep tests are also available at $500{ }^{\circ} \mathrm{C}$ and $600{ }^{\circ} \mathrm{C}$. The main difficulty in this kind of identification is to determine the critical resolved shear stress of each system. As noted previously (Paton et al., 1976), the prismatic slip $\{10 \overline{1} 0\}\langle 11 \overline{2} 0\rangle$ occurs from room temperature, and for temperatures greater than $400{ }^{\circ} \mathrm{C}$ the activation of the basal slip system $\{0001\}\langle 11 \overline{2} 0\rangle$ is also possible. Moreover, the CRSS of the prismatic slip system is always lower than that necessary for the basal slip. Note that using metallographic observations, it has been confirmed that the slip systems activated in the unreinforced matrix are the same as in the matrix in the composite. Using these informations, it is possible to use the identification tools available in the finite element code ZéBuLoN. From a practical viewpoint, the method used consists in comparing all the experimental results (tensile, cyclic and creep tests) for a given temperature with the corresponding responses given by the model. An optimization method is used to determine the parameters leading to the model results. In order to improve this identification it would be necessary to perform several tests on monocrystalline Ti-6242 samples; however, such test specimens are very difficult to obtain in this Ti alloy.

\subsection{Maximum shear stress in the matrix of a SiC/Ti composite subjected to a transverse loading}

Before taking the local texture into account through the polycrystalline aggregate model, the orientation of the planes of maximum shear stress in the matrix will be determined in order to better understand the possible role of the local texture. As noted in Section 2.2, the residual stresses are not taken into account in this first approach. 
In fact, as regards the plastic deformation of the polycrystalline matrix, the quantity of interest is the maximum shear stress acting on the possible slip systems of each grain. This stress is evaluated in the $\left(1^{\prime}, 2^{\prime}, 3^{\prime}\right)$ system of axes, such that the $\left(\sigma_{1^{\prime}}, \sigma_{2^{\prime}}, \sigma_{3^{\prime}}\right)$ stress system is principal. For example, if $\sigma_{1^{\prime}}>\sigma_{2^{\prime}}>\sigma_{3^{\prime}}>0$, then the maximum shear stress, which governs the possibility of plastic deformation by dislocation glide in the slip plane, attains the maximum value of $\tau_{\max }=\left(\sigma_{1^{\prime}}-\sigma_{3^{\prime}}\right) / 2$ in the planes making an angle of $\pm 45^{\circ}$ with respect to the directions $1^{\prime}$ and $3^{\prime}$. The condition of generalized plane strain is considered in the axial direction $\left(\varepsilon_{33}\right.$ uniform). The values of the plane stresses $\sigma_{13}$ and $\sigma_{23}$ are negligible as compared with the other components of the stress tensor. In order to simplify the discussion, the direction 3 and the stress component $\sigma_{33}$ (fibre axis) are supposed to be principal. In order to determine the maximum shear stress and identify the corresponding plane, it is necessary to determine, at each Gauss point, the system of axes such that the stress system is principal. FE calculations in the elastic domain, without taking into account the internal thermal stresses, have been performed using the unit cell presented in Section 2. The maximum shear stress in the matrix is represented as grey levels density maps (Figs. 5 and 6); the two principal directions giving this maximum shear stress are also reported. The results are presented in Fig. 5 in the case of a perfectly bonded interface, whereas those corresponding to the case of a perfectly debonded interface are given in Fig. 6. In both cases, the maximum shear stress may be compared to that attained in a continuous medium (0.5). It should also be noted that in the case of complete debonding, the problem is not exactly the same as that of a hole (maximum shear stress 1.5), but that of a hole with an inserted bar. The maximum shear stress would thus be attributed both to the finite geometry effects (boundary conditions instead of infinite plate) and to the presence of the inserted fibre.

- Perfectly bonded interface: the two directions giving the maximum shear stress are close to the directions 1 and 2. The maximum shear stress is attained in the matrix regions located between the fibres aligned in the loading direction 1. This means that plastic deformation will occur in this part of the matrix (Fig. 5). The maximum shear stress attains the maximum value of $\tau_{\max }=$ $\left(\sigma_{1^{\prime}}-\sigma_{2^{\prime}}\right) / 2$ in the planes making an angle of $\pm 45^{\circ}$ with respect to the directions $1^{\prime}$ and $2^{\prime}$. The shear stress $\left(\sigma_{3^{\prime}}-\sigma_{2^{\prime}}\right) / 2$ in the planes making an angle of $\pm 45^{\circ}$ with respect to the directions $2^{\prime}$ and $3^{\prime}$ is lower, and finally the shear stress $\left(\sigma_{1^{\prime}}-\sigma_{3^{\prime}}\right) / 2$ in the planes making an angle of $\pm 45^{\circ}$ with respect to the directions $1^{\prime}$ and $3^{\prime}$ is the lowest.

- Perfectly debonded interface: The maximum shear stress is attained near the fibres in the matrix regions located at $\pm 90^{\circ}$ to the loading axis. Plastic deformation will thus occur in this part of the matrix. In these regions, the two directions giving the maximum shear stress are close to the directions 1 and 2 (Fig. 6); the maximum shear stress attains the maximum value of $\tau_{\max }=\left(\sigma_{1^{\prime}}-\sigma_{2^{\prime}}\right) / 2$ in the planes making an angle of $\pm 45^{\circ}$ with respect to the directions $1^{\prime}$ and $2^{\prime}$. In these regions, the maximum shear stress resulting from the stress components $\sigma_{3^{\prime}}$ and $\sigma_{2^{\prime}}$ is lower, and finally the maximum shear 


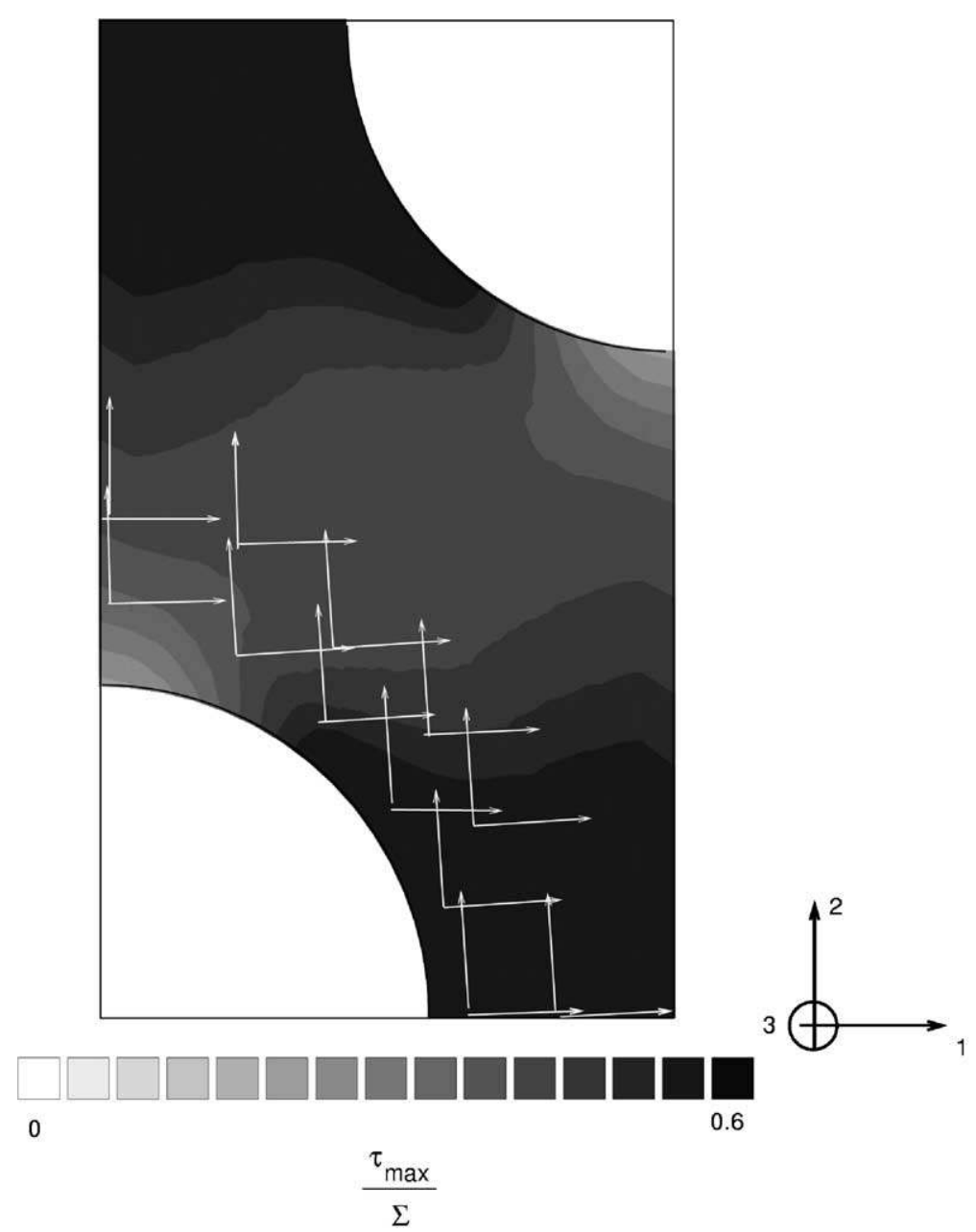

Fig. 5. The normalized maximum shear stress in the matrix and the two principal directions giving this maximum shear stress in the case of a perfectly bonded interface. The transverse loading direction is horizontal.

stress resulting from the stress components $\sigma_{1^{\prime}}$ and $\sigma_{3^{\prime}}$ is the lowest. In the regions located in the loading direction, the maximum shear stress, although much lower than that attained in the regions located at $\pm 90^{\circ}$ to the loading axis, is either the $\left(\sigma_{3^{\prime}}-\sigma_{2^{\prime}}\right) / 2$ or $\left(\sigma_{1^{\prime}}-\sigma_{3^{\prime}}\right) / 2$ maximum shear stresses.

These results indicate that:

- in both cases (perfectly bonded or perfectly debonded interfaces), the maximum shear stress attains its maximum value in the planes making an angle of $\pm 45^{\circ}$ with respect to principal directions very close to directions 1 and 2 . 


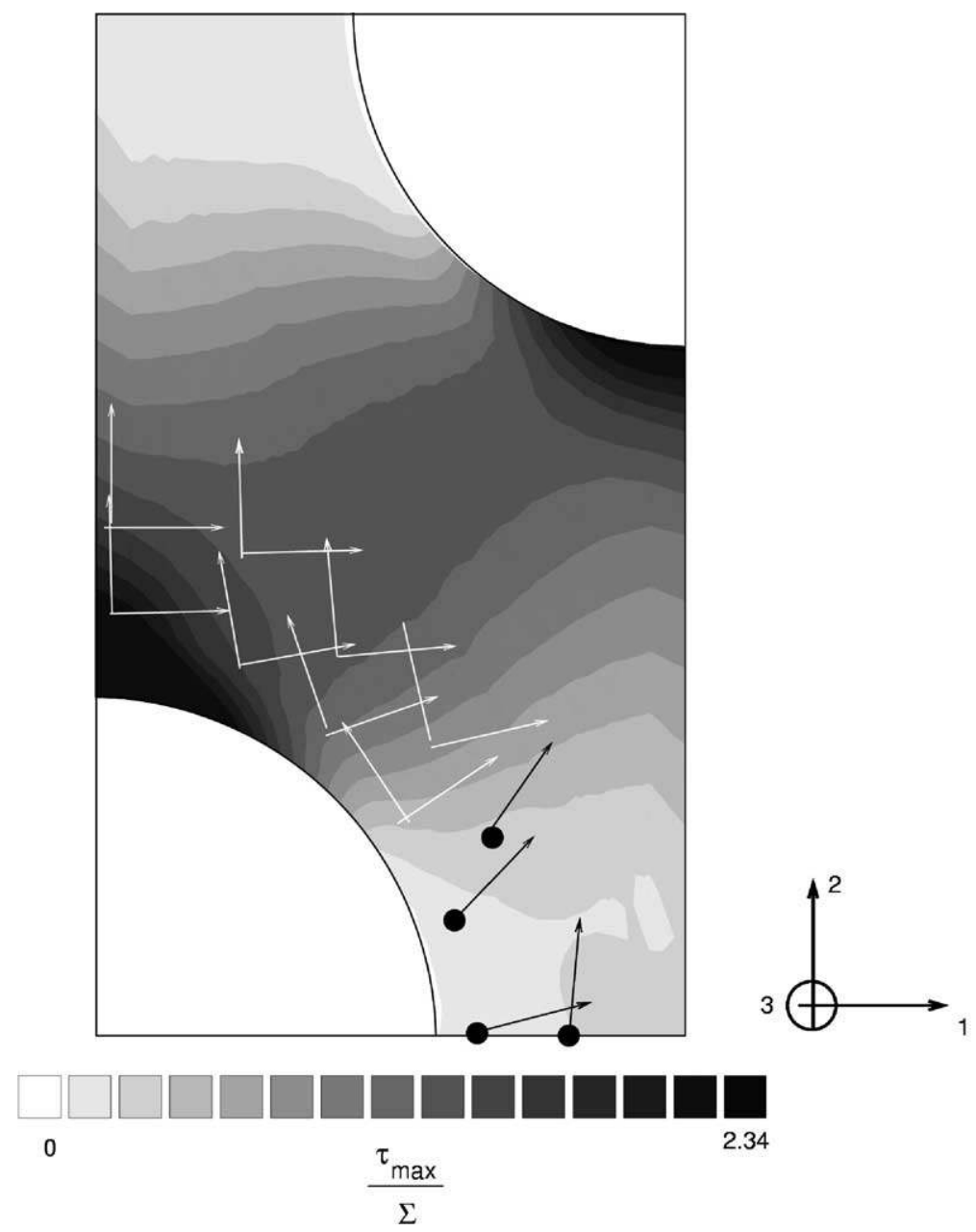

Fig. 6. The normalized maximum shear stress in the matrix and the two principal directions giving this maximum shear stress in the case of a perfectly debonded interface. The transverse loading direction is horizontal.

- in the perfectly bonded interface case, plastic deformation will occur in the regions located between the fibres aligned in the loading direction, whereas in the perfectly debonded case, plastic deformation will occur in the regions at $\pm 90^{\circ}$ to the loading axis.

\subsection{Complete modelling of a SiC/Ti composite subjected to transverse loadings}

These FE calculations have also been performed using the unit cell presented in Fig. 1. The matrix is represented by the previously described polycrystalline aggregate 
model, 40 grain orientations being taken into consideration under each Gauss Point, using the orientations of the grains determined by the EBSD technique (isotropic in zone B and textured in zone A). As mentioned in Section 2, the progressive interfacial debonding and the residual stresses are now taken into account.

Taking the matrix texture into account, the parameters of the interfacial debonding model have been identified in order to numerically reproduce the transverse tensile curve experimentally obtained on the SM1140+/Ti-6242 composite. This procedure of identification is reported in a previous paper (Carrere et al., 2002) and briefly explained in Section 2.2. It should be noted that the corresponding critical energy release rates are lower than in the case where the matrix is described by an isotropic elastoviscoplastic model. A possible explanation for this difference is that the isotropic elastoviscoplastic model does not correctly describe the nature of the matrix in the composite. Then, a part of the phenomena related to the matrix was integrated in the interface behaviour.

The interfacial parameters being thus determined, the calculation of the transverse creep curves is then possible. The creep curves obtained experimentally and numerically using the polycrystalline model (noted "poly"), for tests performed at $220 \mathrm{MPa}$ (lower than the critical stress) and $300 \mathrm{MPa}$ (higher than the critical stress) are reported in Fig. 7. Only two representative tests are reported for the sake of conciseness. It should be noted that the same comparison between experimental and numerical results has been performed for all the investigated creep tests reported in Carrere et al. (2002).

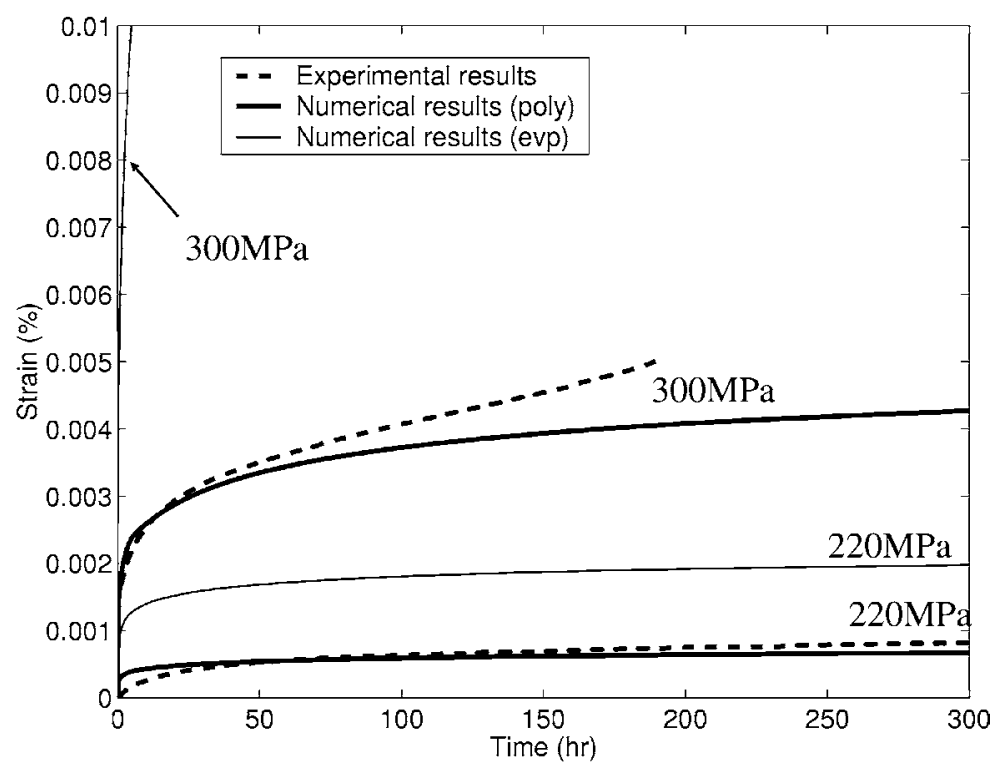

Fig. 7. Comparison between experimental and numerical results (polycrystalline model taking into account the matrix texture), for transverse creep tests performed on the SM1140+/Ti-6242 composite at $500{ }^{\circ} \mathrm{C}(220 \mathrm{MPa}$ and $300 \mathrm{MPa})$. The numerical results corresponding to transverse creep tests at $500{ }^{\circ} \mathrm{C}$ (220 MPa and $300 \mathrm{MPa}$ ), obtained using the isotropic elastoviscoplastic model (evp), are also reported. 
The results of numerical creep tests at $220 \mathrm{MPa}$ and $300 \mathrm{MPa}$ obtained using a classical two-scale approach (an isotropic elastoviscoplastic model is used to describe the matrix), have also been reported (noted "evp"). In this last case, the primary creep stage is too high as compared with the experimental result. On the contrary, for the two investigated stresses, there is a good agreement between the numerical creep curves obtained using the polycrystalline model and the experimental creep curves. An inverse identification has also been performed, using composite transverse creep tests, in order to re-identify the macroscopic elastoviscoplastic model of the matrix. Unfortunately, even using these modified parameters, it has not been possible to obtain a good description of the composite transverse creep behaviour for all the investigated stresses. These results clearly demonstrate the necessity of taking into account the crystalline nature of the titanium alloy and the local texture of the matrix in order to correctly describe the composite behaviour.

At the matrix grain scale in the composite, it is possible to identify the slip systems numerically activated during a calculated transverse creep test $\left(500{ }^{\circ} \mathrm{C}\right)$, as a function of the applied stress. For a test performed at $220 \mathrm{MPa}$ (lower than the critical stress), plastic deformation essentially occurs by slip in the basal plane, whereas at $300 \mathrm{MPa}$ (greater than the critical stress), plastic deformation occurs by slip in the prismatic and basal planes. This result is very surprising because in the monolithic matrix the prismatic slip is activated first and the basal slip is only activated for the highest stresses. An explanation will be given in the next section.

Modelling of transverse tensile tests at $20^{\circ} \mathrm{C}$ have also been performed. In those numerical transverse tensile tests, the loading direction is either the classical transverse direction (RD) or the through-thickness direction (ND) (Figs. 8 and 9). Two modellings have been performed: (1) using the three-scale model developed in the present work (noted "poly") and (2) using a classical two-scale approach (noted "evp"). The aim of these modellings is to determine the influence of a crystallographic anisotropy of the matrix on the macroscopic behaviour of the composite. In this respect, a first experimental response is given by Thomas (2000) on a SM1140 + /Ti-64 composite manufactured by the foil/fibre/foil technique. Although the local texture of this composite has not been determined, it may be assumed to be similar to that measured in the present study (same fibres, very similar matrix and same consolidation process). The experimental results obtained by Thomas (2000) have revealed a strong difference in the mechanical properties in the RD and ND directions: the mechanical strength is higher in the RD than in the ND direction. The results of the finite element calculations, using the three-scale approach, are presented in Fig. 8a. In fact, a strong mechanical anisotropy between the transverse tensile tests performed in the RD and ND directions is evidenced when the threescale approach is used, taking into account the local textured polycrystalline nature of the matrix: the yield stress is higher in the RD than in the ND direction. Fig. 8b presents the results obtained using a classical isotropic elastoviscoplastic model; in this last case, the numerical responses in the RD and the ND directions are identical. Consequently, taking into account the local texture of the matrix allows to reproduce qualitatively the experimental results obtained by Thomas (2000). Moreover, 

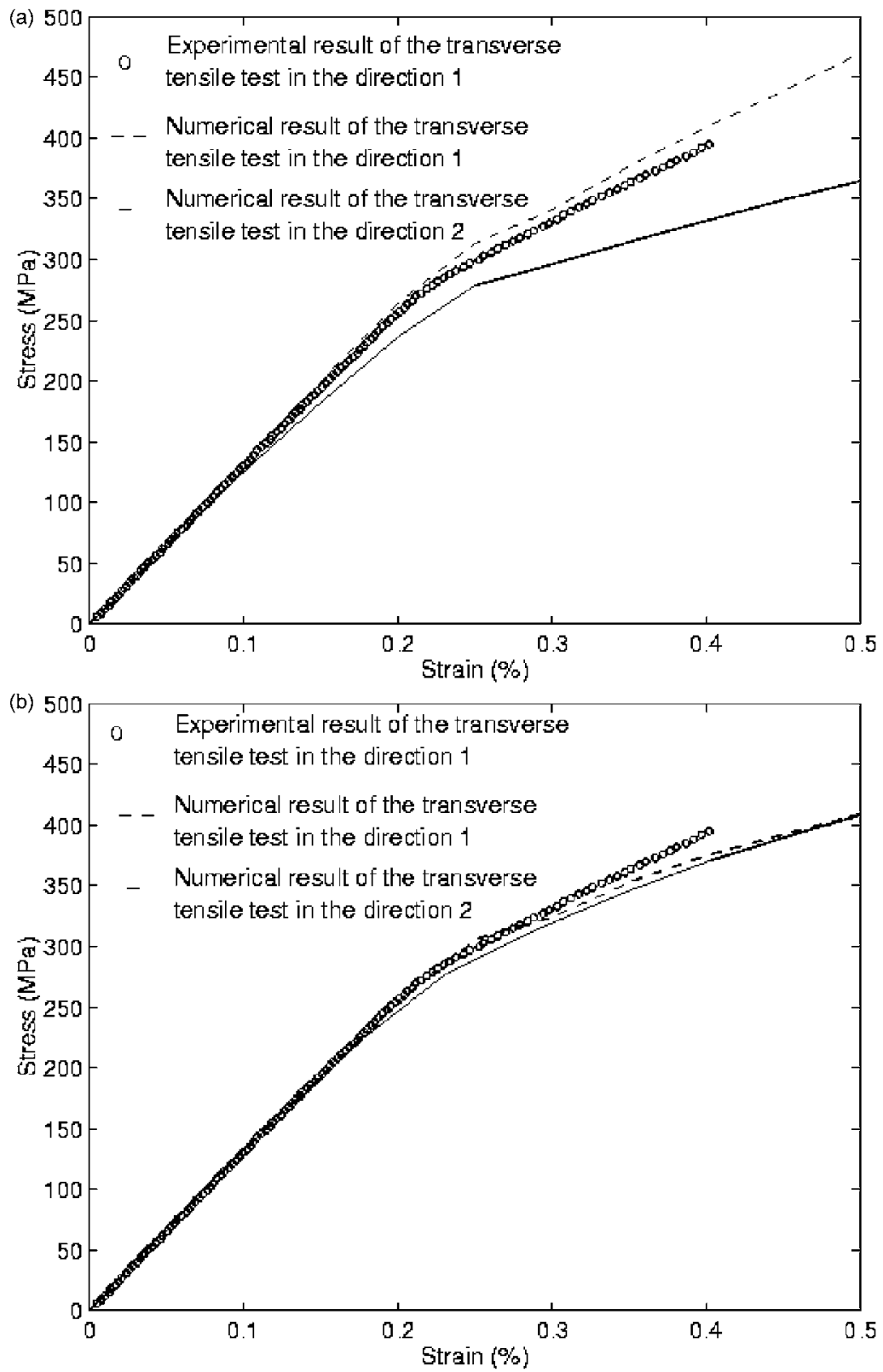

Fig. 8. Numerical results of transverse tensile tests $\left(20^{\circ} \mathrm{C}\right)$ in the directions 1 and 2 using the three-scale approach (polycrystalline model) (a) and using the classical two-scale approach (isotropic elastoviscoplastic model) (b). 

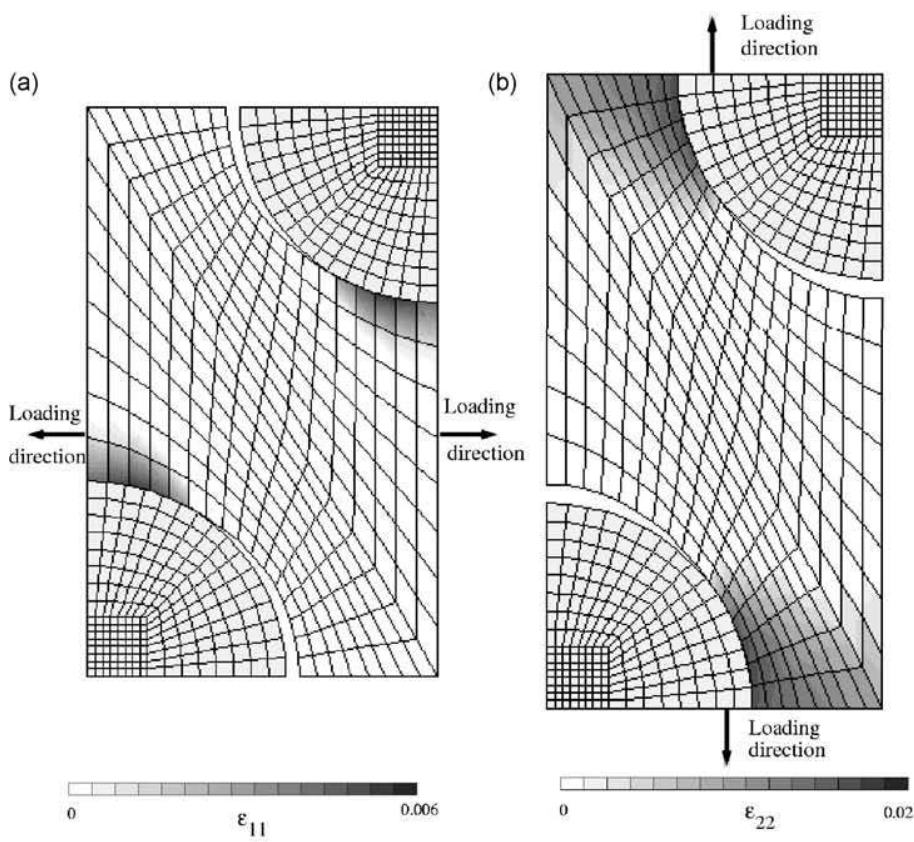

(c)

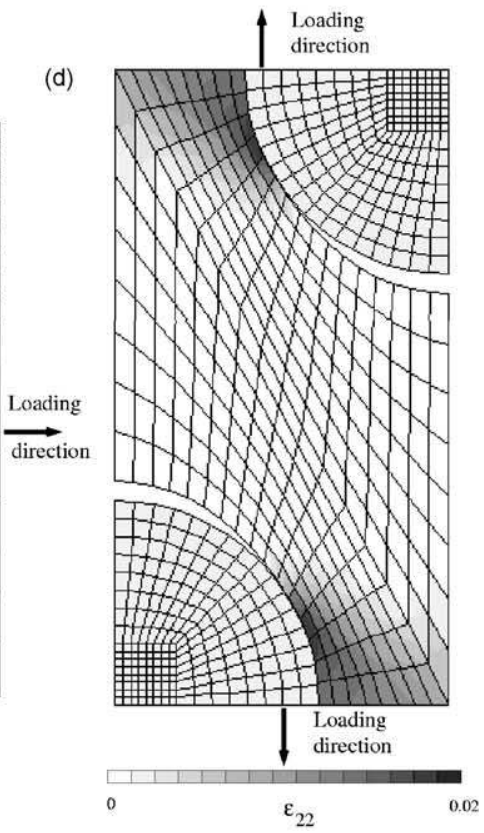

Fig. 9. Local plastic strain in the direction of loading [i.e. $\varepsilon_{11}$ (a and c) and $\varepsilon_{22}$ (b and d)] for transverse tensile tests in the directions 1 and 2 using the three-scale approach (polycrystalline model) (a and b) and using the classical two-scale approach (c and d). 
the local plastic strain in the direction of loading obtained using a three-scale approach (a and b) and a classical two-scale approach (c and d) is reported in Fig. 9. When the composite is subjected to a transverse loading, the deformation is localized in regions located $\pm 90^{\circ}$ to the loading axis. When using an elastoviscoplastic model for the matrix (Fig. 9c and d), the plastic strains are very similar for the transverse tensile tests performed in the RD and ND directions. However, when the polycrystalline textured nature of the matrix is taken into account, the plastic strains are three times higher for the ND tensile test than for the RD tensile test (Fig. 9a and b). These local results are in a good agreement with the macroscopic ones (Fig. 8) and show that it is of absolute necessity to take into account the local texture of the matrix in order to describe both the local and the global behaviour of the composite.

\section{Summary and discussion}

The results presented in the previous section have demonstrated that taking into account the local texture of the matrix in the composite, permits to quantitatively reproduce the experimental results. A mechanical anisotropy between the two transverse directions, due to the plastic anisotropy of the matrix resulting from the crystallographic texture has also been evidenced. These results may be explained in terms of maximum shear stress acting on the possible slip systems of each grain (see Section 3.3). The discussion will be focused on the use of these results in order to improve the mechanical properties of $\mathrm{SiC} / \mathrm{Ti}$ composites.

\subsection{Influence of the texture on the transverse creep behaviour of a SiC/Ti composite}

As noted in the previous section, for a numerical creep test performed at $500{ }^{\circ} \mathrm{C}$ under the stress leading to the interface failure, the calculated plastic deformation essentially occurs by slip in the basal slip plane, whereas for higher stresses, plastic deformation occurs by slip in the prismatic and basal slip planes. This result, summarized in Fig. 10, is very surprising because, in the monolithic matrix, whatever the temperature, the stress necessary to activate the prismatic slip is lower than that necessary to activate the basal slip. In fact, the local texture of the matrix and the triaxial stress state in the matrix permit to explain this behaviour

- for low applied loadings, the interface is partially debonded (the stress state is similar to that of Fig. 6). The plastic deformation will thus occur in the regions located at nearly $\pm 90^{\circ}$ to the loading axis; plastic deformation thus takes place in the matrix regions where the texture is maintained. The maximum shear stress attains its maximum value in the planes making an angle of $\pm 45^{\circ}$ with respect to directions very close to the directions 1 and 2. Due to the strong local matrix texture in these regions, the maximum shear stress is thus attained in planes located near the basal plane. In this case of only partial debonding, load transfer to the fibre is partially maintained, the resolved shear stress in the prismatic planes is thus not high enough to activate the prismatic slip. 
- for high applied loadings, the interface is totally broken. The stresses are transferred to the matrix. The stress state is high enough to activate both the prismatic and basal slip systems which lead to a large plastic deformation.

\subsection{Influence of the texture on the mechanical anisotropy of a SiC/Ti composite}

The influence of the crystallographic and thus plastic anisotropy of the matrix on the macroscopic behaviour has also been evidenced. This other result could be explained using the same argumentation. At $20^{\circ} \mathrm{C}$, plastic deformation only occurs

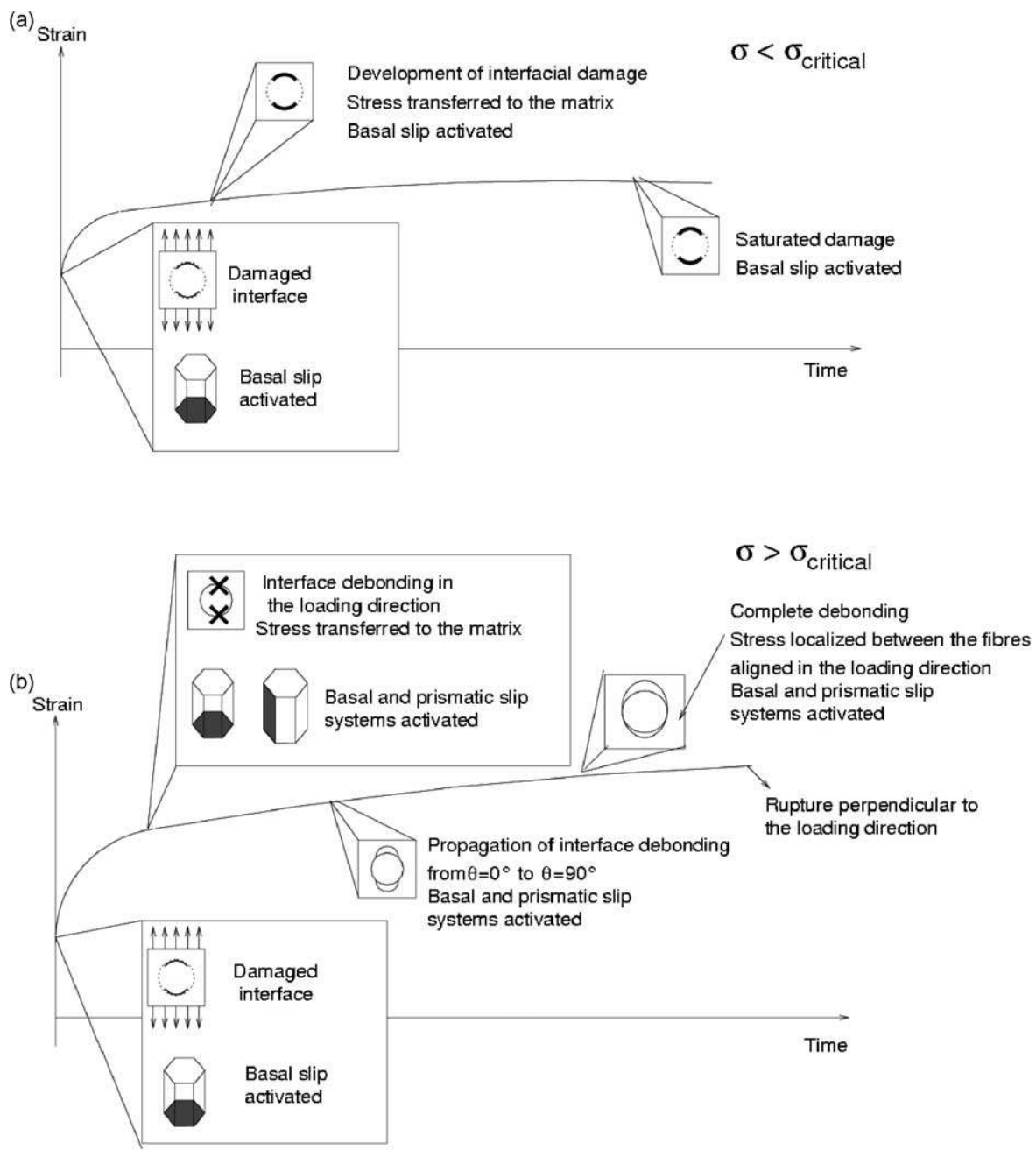

Fig. 10. Damage evolution and plastic deformation mechanisms activated as a function of the applied stress, (a) below the critical stress and (b) above the critical stress. 
by slip in the prismatic slip planes. The initiation of interfacial damage begins in the loading direction and increases progressively around the fibre. After complete debonding, the maximum shear stress is localized in the regions located at $\pm 90^{\circ}$ to the loading axis.

- when the composite is subjected to a transverse loading in the classical transverse direction (RD or direction 1), the stress is localized in the regions located at $\pm 90^{\circ}$ to the direction 1 (where the texture of the matrix is maintained). Using the same developments as presented in Section 3.3 and used in Section 4.2, it can be shown that in this region, due to the local texture, there is no prismatic plane favourably oriented as regards the possibility of plastic deformation.

- when the composite is subjected to a transverse loading in the throughthickness direction (ND or direction 2), the stress is localized in the regions located at $\pm 90^{\circ}$ to the direction 2 (where the matrix is isotropic). The matrix being isotropic in these regions, there is a number of prismatic planes favourably oriented as regards plastic deformation. The yield stress is consequently lower when the composite is subjected to a transverse loading exerted in the ND direction than in the RD direction.

\subsection{Improvement in the transverse behaviour of a SiC/Ti composite by a specific texture}

In a fundamental deformation mode approach, the macroscopic behaviour of a $\mathrm{SiC} / \mathrm{Ti}$ composite subjected to a transverse loading could be explained in terms of maximum shear stress acting on the prismatic system (which has the lower critical resolved shear stress) of each grain. Consequently, the macroscopic behaviour could be changed by modifying the texture

- in a matrix presenting a strong texture such that the $\langle 0002\rangle$ direction is parallel to the direction 3 [Fig. 11 (a)], there is a number of prismatic planes in
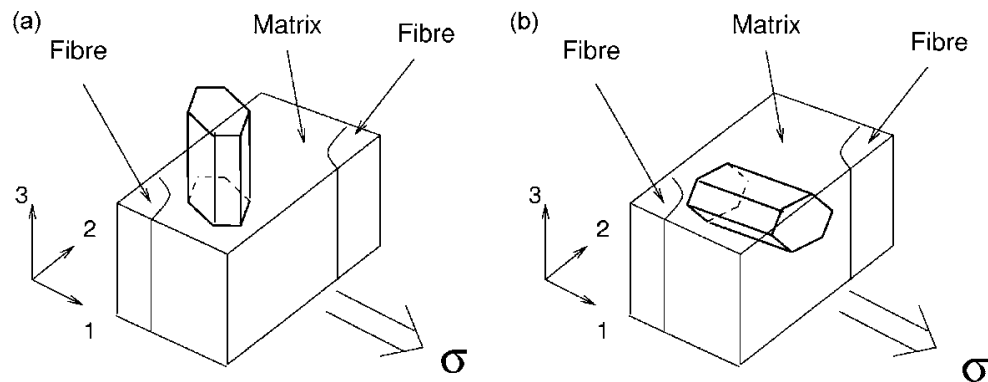

Fig. 11. Representation of the crystallographic orientations of the matrix grains leading to the lowest yield strength (a) and to the highest yield strength (b). 
which the shear stress is maximum, thus leading to a low yield strength.

- in a textured matrix such that the $\langle 0002\rangle$ direction is parallel to the direction 1 [Fig. 11(b)], the crystals are so oriented that the shear stress in the prismatic planes is minimum, leading to a high yield strength.

These results demonstrate that a change in the matrix texture leads to a change in the macroscopic composite behaviour. Modifying the texture of the matrix is possible using different fibre mats (plasma sprayed monotapes, matrix coated fibres...). Consequently, the present analysis could help the composite manufacturers to choose between the various processing routes in order to improve the composite behaviour.

\section{Conclusion}

As mentioned previously, the present study was devoted to demonstrate that the texture of the matrix of a $\mathrm{SiC} / \mathrm{Ti}$ composite has a large influence on the macroscopic behaviour of this composite. A three-scale approach was used: from the grain scale to the macroscopic scale.

- A local matrix texture has been evidenced using the EBSD technique. In a part of the matrix (the central part of the matrix foils, zone A) the foil texture is maintained whereas the rest of the matrix (interfibre spacing, zone B) becomes isotropic.

- In order to study the influence of this texture on the composite behaviour, FE calculations have been undertaken. In a first approach, the computations have been performed in linear elasticity in order to obtain quantitative informations concerning the maximum shear stress in the matrix. The internal stress field resulting from the mismatch between the coefficients of thermal expansion was not taken into account. These results already suggest that a change in the matrix texture could lead to a change in the macroscopic composite behaviour.

- The complete modelling of a $\mathrm{SiC} / \mathrm{Ti}$ composite subjected to transverse loadings has been undertaken. This modelling takes into account the polycrystalline nature of the matrix, the local matrix texture, the progressive interfacial debonding and the residual stresses due to the consolidation process. In this context, let us note the exceptional character of the present analysis which simultaneously incorporates two scale changes: (1) from the crystal plasticity in each grain in the matrix to the viscoplastic behaviour of this polycrystalline matrix (under each Gauss Point in the FE model), (2) from the matrix, interface and fibre behaviour to the overall composite behaviour by periodic homogenization using a FE unit cell technique. The comparison between experimental and numerical results clearly demonstrates that it is necessary to take into account the texture of the matrix in the modelling. It has been evidenced, as a result of this modelling, that the 
crystallographic anisotropy of the matrix leads to a mechanical anisotropy of the composite. From an industrial viewpoint, this effect is so important, that it will be necessary to take this mechanical anisotropy into account when designing industrial components.

The results presented in this paper have helped clarifying the relation between the "sub-microscopic" scale (matrix grain scale) and the macroscopic scale (global composite behaviour). As shown in previous articles, it has been demonstrated in this paper that the damage composite behaviour is influenced by the residual stresses and the interfacial behaviour. It has also been shown that the local matrix texture has a great influence on the viscoplastic composite behaviour. It permits to propose ways of improvement of the mechanical behaviour of $\mathrm{SiC} / \mathrm{Ti}$ composites by modifying the interfacial resistance and changing the matrix texture. This last point is possible by using different fibre mats (plasma sprayed monotapes, triode sputtering technique coated fibres...) whose textures are strongly different (Carrere, 2001). Also note that during a creep test (which is representative of the mechanical loading in the rotating disc), there is a strong interaction between damage and viscoplasticity. However, the analysis presented here only consider a unidirectional macroscopic transverse loading. In fact, in order to be more representative of the real situation, it would be necessary to take into account a macroscopic multiaxial stress state (macroscopic longitudinal and transverse stresses). Nevertheless, it has been shown that taking into account the residual stresses, the interfacial behaviour and matrix texture in the modelling is the only way to quantitatively reproduce the experimental results. The modelling presented in this paper is totally predictive. The effect of a change in fibre nature, fibre volume fraction or matrix texture is possible and is presently under investigation.

The last step is the complete modelling of a structure (reinforced turbine disc for example) taking into account the real microstructure of the composite (fibre, polycrystalline matrix, interface). This problem is presently under investigation at Onera (Pottier, 1998; Chaboche et al., 2001) in order to perform simulations from the "submicro" scale to that of the structure (four-scale approach), using for instance the $\mathrm{FE}^{2}$ numerical technique (Feyel, 1998, 1999) including a polycrystalline aggregate micro-mechanics model for the modelling of the matrix behaviour.

\section{Acknowledgements}

The authors would like to express their sincere gratitude to Mrs. M. Raffestin for the preparation of the samples. They would also like to thank D. Boivin for the EBSD determination of textures and Drs. S. Kruch and F. Feyel for valuable discussions concerning the Finite Elements calculations. The support of SNECMA for manufacturing the composite plate is also acknowledged. 


\section{References}

Barbe, F., Decker, L., Jeulin, D., Cailletaud, G., 2001. Intergranular and intragranular behavior of polycrystalline aggregates part 1 and 2. Int. J. Plast. 17, 513-563.

Baroumes, L., 1998. Comportement des Composites à Matrice Métallique: du processus de fabrication à la tenue en service. Doctorate Thesis, Ecole Normale Supérieure de Cachan.

Berveiller, M., Zaoui, A., 1978. An extension of the self-consistent scheme to plastically flowing polycrystals. J. Mech. Phys. Solids 26, 325-344.

Brockenbrough, J.R., Suresh, S., Wienecke, H.A., 1991. Deformation of metal-matrix composites with continuous fibers : geometrical effect of fiber distribution and shape. Acta Metall. Mater. 39 (5), $735-$ 752.

Burlet, H., Cailletaud, G., 1991. Zebulon, a finite element code for nonlinear material behaviour. In: Ladevèze, P. et al. (Eds), Proc. Eur. Conf. on New Advances in Computational Structural Mechanics, Giens, France, pp. 673-680.

Cailletaud, G., 1987. Une approche micromécanique phénoménologique du comportement inélastique des métaux. Doctorate Thesis, Université Paris 6.

Cailletaud, G., 1992. A micromechanical approach to inelastic behaviour of metals. Int. J. Plasticity 8, 5573.

Cailletaud, G., Pilvin, P., 1994. Utilisation des modèles polycristallins. Revue Européenne des Elements Finis 3, 515-541.

Carrere, N., 2001. Sur l'analyse multiéchelle des matériaux composites à matrice métallique: application au calcul de structure. Doctorate Thesis, Ecole Polytechnique.

Carrere, N., Boivin, D., Valle, R., Vassel, A., 2001. Local texture measurements in a SiC/Ti composite manufactured by the foil-fibre-foil technique. Scripta Mater. 44, 867-872.

Carrere, N., Kruch, S., Vassel, A., Chaboche, J.-L., 2002. Damage mechanisms in unidirectional SiC/Ti composites under transverse creep loading: experiments and modeling. Int. J. Damage Mech. 11, 41-63.

Chaboche, J.-L., Girard, R., Schaff, A., 1997. Numerical analysis of composite systems by using interphase/interface model. Computational Mech. 20, 3-11.

Chaboche, J.-L., Kruch, S., Maire, J.-F., Pottier, T., 2001. Towards a micromechanics based inelastic and damage modeling of composites. Int. J. Plasticity 17, 411-439.

Cheng, T.T., Jones, I.P., Shatwell, R.A., Doobar, P., 1999. The microstructure of sigma $1140+$ SiC fibres. Mater. Sci. Eng. A260, 139-145.

Cotterill, P.J., Bowen, P., 1996. Transverse properties of a Ti-6-4 matrix/SiC fibre-reinforced composite under monotonic and cyclic loading. J. Mater. Sci. 31, 5897-5905.

Crossman, F.W., Karmak, R.F., Barnett, D.M., 1974. Creep of B/Al composites as influenced by residual stresses, bond strength and fiber packing geometry. In: Fleck, J.N., Mehan, R.L. (Eds.), Failure Modes in Composites II, pp. 8-21.

Dève, H.E., 1999. Effect of fiber spatial arrangement on the transverse strength of titanium matrix composites. Metall. Mater. Trans. 30A (9), 2513-2522.

Durodola, J.F., Ruiz, C., Derby, B., 1994. Uniaxial creep of long fibre reinforced metal matrix composites. Composites Engineering 4, 1241-1255.

Eggleston, M.R., Ritter, A.M., 1995. The transverse creep deformation and failure characteristics of SCS6/Ti-611-4V metal matrix composites at $428^{\circ} \mathrm{C}$. Metall. Mater. Trans. 26A, 2733-2744.

Ellyin, F., Xia, Z., 2001. Rate-dependent constitutive modelling and micro-mechanical analysis of fibrereinforced metal-matrix composites. J. Mech. Phys. Solids 49, 2543-2555.

Feaugas, X., Pilvin, P., Clavel, M., 1997. Cyclic deformation behaviour of an $\alpha / \beta$ titanium alloy-II. Internal stresses and micromechanic modelling. Acta Mater. 43 (7), 2703-2714.

Feyel, F., 1998. Application du calcul parallèle aux modèles à grand nombre de variables internes. Doctorate Thesis, Ecole Nationale Supérieure des Mines de Paris.

Feyel, F., 1999. Multiscale FE2 elastoviscoplastic analysis of composite structures. Comput. Mater. Sci. $16,344-354$.

Gordon, F.H., Clyne, T.W., 1993. The effects of texture and microstructure on the thermal cycling creep 
of Ti-6Al-4V with and without fiber reinforcement. In: Miravete A. (Ed.), Proceedings of the 9th Int. Conference on Composite Materials, Vol. 1, pp. 524-532.

Gundel, D.B., Majumdar, B.S., Miracle, D.B., 1995. Evaluation of the transverse response of fibre-reinforced composites using a cross-shaped sample geometry. Scripta Metall. Mater. 33, 2057-2065.

Kröner, E., 1961. Zur plastischen Verformung des Vielkristalls. Acta Metall. 9, 155-161.

Lesne, P.-M., Allio, N., Valle, R., 1995. Combined effects of the fibre distribution and of the fiber matrix or interphase matrix transverse modulus ratio on the possible fracture modes of unidirectional composites submitted to a transverse loading. Acta Metall. Mater. 43 (12), 4247-4260.

Li, D.S., Wisnom, M.R., 1994. Unidirectional tensile stress-strain response of BP-SiC fiber-reinforced Ti-6Al-4V. J. Comp. Techn. Res. 16, 225-233.

Lin, T.H., 1957. Analysis of elastic and plastic strains of a F.C.C. crystals. J. Mech. Phys. Solids 5, $143-149$.

Majumdar, B.S., Newaz, G.M., 1992. Inelastic deformation of metal matrix composites: plasticity and damage mechanisms. Phil. Mag. A66 (2), 187-212.

Mall, S., Fecke, T., Foringer, M.A., 1998. Introduction. In: Mall, S., Nicholas, T. (Eds.), Titanium Matrix Composites: Mechanical Behavior, pp. 1-22.

Malon, S., 2000. Caractérisation des mécanismes d'endommagement dans les composites à matrices métalliques. Doctorate Thesis, Ecole Normale Supérieure de Cachan.

Masson, R., Bornert, M., Suquet, P., Zaoui, A., 2000. An affine formulation for the prediction of the effective properties of nonlinear composites and polycrystals. J. Mech. Phys. Solids 48, 1203-1227.

Méric, L., Poubane, P., Cailletaud, G., 1991. Single crystal modeling for structural calculations: part 1model presentation. Trans. ASME: J. Eng. Mater. Techn. 113, 162-170.

Miracle, D.B., Majumdar, B.S., 1999. Transverse creep of SiC/Ti-6Al-4V fiber-reinforced metal matrix composites. Metall. Mater. Trans. 30A (2), 301-306.

Molinari, A., El Houdaigui, F., Toth, L. S., 2003. Validation of the tangent formulation for the solution of the non-linear Eshelby inclusion problem. Int. J. Plast. Article (in press).

Nakamura, T., Suresh, S., 1993. Effects of thermal residual stresses and fiber packing on deformation of metal-matrix composites. Acta Metall. Mater. 41 (6), 1665-1681.

Needleman, A., 1987. A continuum model for void nucleation by inclusion debonding. Trans. ASME: J. Appl. Mech. 54, 525-531.

Needleman, A., 1992. Micromechanical modelling of interfacial decohesion. Ultramicroscopy 40, $203-214$.

Needleman, A., Tvergaard, V., 1993. Comparison of crystal plasticity and isotropic hardening predictions for metal-matrix composites. Trans. ASME: J. Appl. Mech. 60, 70-76.

Nimmer, R.P., 1990. Fiber-matrix interface effects in the presence of thermally induced residual stresses. J. Comp. Techn. Res. 12, 65-75.

Nimmer, R.P., Bankert, R.J., Russel, E.S., Smith, G.A., Wright, P.K., 1991. Micromechanical modelling of fibre/matrix interface effects in transversely loaded SiC/Ti-6-4 metal matrix composites. J. Comp. Techn. Res. 13, 3-13.

Ohno, N., Toyoda, K., Okamoto, N., Miyake, T., Nishide, S., 1994. Creep behaviour of a unidirectional SCS-6/Ti-15-3 metal matrix composite at $450{ }^{\circ}$ C. Trans. ASME: J. Eng. Mater. Techn. 116, $208-214$.

Paton, N.E., Baggerly, R.G., Williams, J.C., 1976. Report AFOSR no. F44620-72-C-0043.

Pilvin, P., 1990. Une approche inverse pour l'identification d'un modèle polycristallin élastoviscoplastique. Doctorate Thesis, Université Paris 6.

Pilvin, P., Cailletaud, G., 1990. Intergranular and transgranular hardening in viscoplasticity. In: Zyczkowski, M. (Ed.), Proceedings IUTAM Symposium Creep in Structures IV, pp. 171-178.

Pilvin, P., 1996. The contribution of micromechanical approaches to the modelling of inelastic behaviour of polycrystals. In: Pineau, A., Cailletaud, G., Lindley, T.C. (Eds.), Multiaxial Fatigue and Design, ESIS 21. Mechanical Engineering Publications, London, pp. 3-19.

Pilvin, P., 1997. Une approche inverse pour l'identification d'un modèle polycristallin élastoviscoplastique. In: Presses Académiques de l'Ouest (Eds), Proceedings 3ieme Colloque National Calcul des Structures, pp. 207-212.

Pochiraju, K.V., Tandon, G.P., Pagano, N.J., 2001. Analysis of single fiber pushout considering interfacial friction and adhesion. J. Mech. Phys. Solids 49, 2307-2338. 
Ponte Castañeda, P., 1996. Exact second order estimates for the effective mechanical properties of non-linear composite materials. J. Mech. Phys. Sol. 44, 827-862.

Ponte Castañeda, P., Suquet, P., 1998. Non linear composites. Adv. Appl. Mech. 34, 171-302.

Poole, W.J., Embury, J.D., Mac Even, S., Kocks, U.F., 1994a. Large strain deformation of a coppertungsten composite system I. Strain distributions. Phil. Mag. A 69 (4), 645-665.

Poole, W.J., Embury, J.D., Mac Even, S., Kocks, U.F., 1994b. Large strain deformation of a coppertungsten composite system II. Applications. Phil. Mag. A 69 (4), 667-687.

Pottier, T., 1998. Modélisation multiéchelle du comportement et de l'endommagement de composites à matrice métallique. Doctorate Thesis, Ecole Nationale des Ponts et Chaussées.

Rangaswamy, P., Daymond, M.R., Bourke, M.A.M., Von Dreele, R., Bennet, K., Jayaraman, N., 2000. Texture and residual strain in two SiC/Ti-6-2-4-2 titanium composites. Metall. Mater. Trans. 31A (3), 889-898.

Shatwell, R.A., 1999. Fiber-matrix interfaces in titanium matrix composites made with sigma monofilament. Mater. Sci. Eng. A259, 162-170.

Staroselsky, A., Anand, L., 2003. A constitutive model for hep materials deforming by slip and twinning: application to magnesium alloy AZ31B. Int. J. Plast. 19, 1843-1864.

Stohr, J.-F., Valle, R., 1975. Mécanismes de déformation de composites de solidification. Interprétation du comportement macroscopique à l'aide d'essais de traction in-situ effectués dans un microscope électronique à haute tension. Phil. Mag. 32, 43-59.

Thomas, M.P., 2000. Through-thickness properties of sigma fibre reinforced titanium matrix composite. In: Proceedings of the 9th Eur. Conf. Composite Materials.

Tvergaard, V., 1990. Effect of fibre debonding in a whisker-reinforced metal. Mater. Sci. Eng. A125, 203213.

Valle, R., 1992. Quantitative investigation of the role of the internal stresses and of dislocation pile-ups in tension and fatigue deformation and fracture using a unidirectionally solidified composite. Phil. Mag. $65,149-176$.

Vassel, A., Vidal-Sétif, M.-H., Rabinovitch, M., Mévrel, R., 1996. Composites métalliques renforcés par fibres longues. La Recherche Aérospatiale 5-6, 421-440.

Vidal-Sétif, M.-H., Valle, R., 1999. Rôle de l'interphase de carbone pyrolytique dans les composites SM1140+/Ti-6242 sollicités en traction sens long et travers et en fatigue oligocyclique. Technical Report RT 3/7400DMSC/N, ONERA.

Warrier, S.G., Rangaswamy, P., Bourke, M.A.M., Krishnamurthy, S., 1999. Assessment of the fiber/ matrix interface bond strength in SiC/Ti-6Al-4V composites. Mater. Sci. Eng. A259, 220-227.

Wu, X., Cooper, C., Bowen, P., 2001. In-situ observations of titanium metal-matrix composites under transverse tensile loading. Metall. Mater. Trans. 32A (7), 1851-1860.

ZéBuLoN. User's Manual. Ecole Nationale Supérieure des Mines de Paris, 2000. 